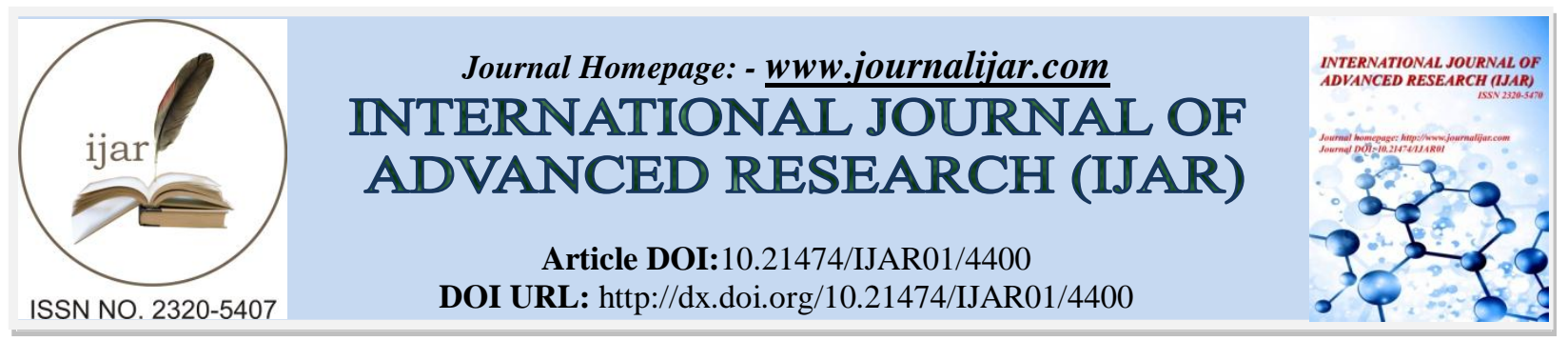

RESEARCH ARTICLE

\title{
REMOVAL OF CARCINOGENIC HEXAVALENT CHROMIUM FROM CONTAMINATED WATER USING ACTIVATED CARBON DERIVED FROM BOMBAX CEIBA BARK.
}

\author{
* Rahangdale P. $\mathbf{K}^{\mathbf{1}}$, Donadkar D. $\mathbf{K}^{\mathbf{2}}$ and Gour $\mathbf{K}^{3}$. \\ 1. Bhawabhuti College, Amgoan-441902, India. \\ 2. Priyadarshini College of Engineering, Nagpur-440019, India. \\ 3. Priyadarshini J. L. College of Engineering, Nagpur-440009, India.
}

\section{Manuscript Info}

Manuscript History

Received: 06 April 2017

Final Accepted: 07 May 2017

Published: June 2017

Key words:-

Activated carbon, carcinogenic chromium, Bombax ceiba, Langmuir

/Freundlich isotherms, pollution control.

\section{Abstract}

\begin{abstract}
Activated carbon was self generated and activated in the laboratory using Bombax ceibabark (naturally available starting raw material), which has been abbreviated as 'ACBCB' and characterized using modern techniques like FTIR and SEM. Adsorptive removal of $\mathrm{Cr}$ (VI) ions from aqueous solution on the adsorbent (ACBCB) has been studied under varying conditions of contact time, adsorbent dose and $\mathrm{pH}$ to assess the kinetic and equilibrium parameters. Maximum adsorption capacity was found to be $97.8 \%$ at optimum $\mathrm{pH} 5.5$ and 110 minutes as optimum contact time. The percentage removal of $\mathrm{Cr}(\mathrm{VI})$ ions was found to increase with increased adsorbent doses from 1 to $7 \mathrm{gm} / \mathrm{lit}$. The adsorption data have been correlated and found that experimental data are well fitted with the Langmuir and Freundlich isotherms. Experimentally obtained appropriate values of sorption parameters derived from Langmuir isotherm like 'Qm'(adsorption efficacy), 'b'(Langmuir constant), R²(Correlation Coefficient square); and the Freundlich constant values( ' $n$ ' and ' $\mathrm{K}_{\mathrm{f}}$ ') derived from Freundlich isotherm proved that the adsorbent 'ACBCB' under present investigation is the best one for efficient removal of Hexavalent Chromium from contaminated water and thus can have potential applications in the field of pollution control.
\end{abstract}

Copy Right, IJAR, 2017,. All rights reserved.

\section{Introduction:-}

Environmental pollution is currently one of the most important issues facing humanity. It was increased exponentially in the past few years and reached alarming levels in terms of its effects on living creatures. Excessive release of heavy metals into the environment due to industrialization and urbanization has posed a great problem worldwide. Heavy metal contamination exists in aqueous wastes of many industries. Toxic heavy metals are considered one of the pollutants that have direct effect on man and animals. Out of the various toxic heavy metal pollutants chromium and its compounds are considered as the most dangerous inorganic water pollutants. Chromium is a chemical element which is derived from the Greek word "chroma" meaning colour, because many of its compounds are coloured. It is the first element in group 6 having atomic number 24 and symbol Cr. Chromium is a hard metal that has high melting point and it is colorless, tasteless and malleable. Chromium in particular has received attention due to its hazardous nature[1,2]. Chromium compounds present in the effluents as a result of electroplating, metal finishing, magnetic tapes, wood preservation, leather tanning, pigments and chemical 
manufacturing industries [3, 4]. It can be present in rocks, soils, plants and animals too. This heavy metal occurs in the environment in two oxidation states: trivalent $\mathrm{Cr}(\mathrm{III})$ and hexavalent $\mathrm{Cr}(\mathrm{VI})$. $\mathrm{Cr}$ (III) is considered as an essential trace nutrient for human, while $\mathrm{Cr}(\mathrm{VI})$ in turn is highly toxic [5, 6]. Because of its mutagenic and carcinogenic properties, its intake may induce skin irritation lung cancer and kidney/liver/gastric damage.[7] Therefore, removal of $\mathrm{Cr}(\mathrm{VI})$ from wastewater is essential before its disposal. Conventional methods for removing dissolved heavy metal ions include chemical precipitation, chemical oxidation /reduction, filtration, ion exchange, electrochemical treatment and membrane technology. These processes have considerable disadvantages such as incomplete metal removal, requirements like expensive equipment and monitoring system, huge amount of reagents and energy and generation of toxic sludge or other waste products that require disposal [8]. Adsorption can be an effective and versatile method for removing chromium particularly when combined with appropriate regeneration steps. This solves the problems of sludge disposal and renders the system more economically viable, especially if low cost adsorbents are used [9-12].

The aim of study was to determine Chromium(VI) ion removal efficiency from aqueous solution using simple adsorption technique onto activated carbon derived from the bark of Bombax ceiba (ACBCB) as a new adsorbent; and analysing the data using Langmuir/ Freundlich isotherms.

\section{Materials and Methods:- Preparation of Adsorbent:-}

Bombax ceibabark was collected from the nearby local forest area of Gadchiroli district and it was cut into small pieces. It was washed with distilled water and dried in sunlight to remove the moisture. Then it was treated with formaldehyde to avoid the release of color by bark into the aqueous solution during the adsorption process. The treated bark was carbonized by slow heating over a wide range of temperature $\left(400-700^{\circ} \mathrm{C}\right)$ in the absence of air in a muffle furnace. The char obtained was subjected to thermal activation in the absence of air at elevated temperature $\left(900^{\circ} \mathrm{C}\right)$ and held at that temperature for $1 \frac{1}{2} 2$ hour. The adsorbent so obtained was ground and sieved through 200 mesh sieves. The dried sample was stored in airtight bottles for further use.

Concentrations of $\mathrm{Cr}(\mathrm{VI})$ ion in solutions were estimated calorimetrically applying standard methods [13, 14]. Standard Cr(VI) solution was prepared by dissolving $0.2829 \mathrm{~g}$ of potassium dichromate crystals in distilled water and making the volume up to $100 \mathrm{~cm}^{3}$. Exactly $50 \mathrm{~cm}^{3}$ of this solution was transferred into a $500 \mathrm{~cm}^{3}$ volumetric flask and made up using distilled water to get a solution containing $0.1 \mathrm{mg}$ of $\mathrm{Cr}(\mathrm{VI})$ ions per $\mathrm{cm}^{3}$. Solutions of various required concentrations were prepared by diluting suitable aliquots of the above solution with distilled water.

\section{Characterization of $\mathrm{ACBCB}$ :- SEM Studies of ACBCB:-}

Fig. 1 shows the SEM image of ACBCB which is obtained using an accelerating voltage of $15 \mathrm{kV}$ at $\mathrm{x} 400$ magnification. SEM micrographs clearly revealed that small pores are presents on the surface of activated carbon(ACBCB) accompanied with fibrous structure. It can also be noticed that the surface structure of $\mathrm{ACBCB}$ is irregular, which would have good capacity of this adsorbent for accumulation of metal ions easily.

\section{FTIR Studies of ACBCB:-}

FTIR spectrum of ACBCB has shown in Fig.2 The band at $3300-3800 \mathrm{~cm}^{-1}$ is due to stretching vibrations of phenolic hydroxyl $(-\mathrm{OH})$ group. The peak at $2359 \mathrm{~cm}^{-1}$ shows presence of bonded $-\mathrm{OH}$ groups involved in Hydrogen bonding. The peaks appeared at 1090.28, 1216.02 and $752.45 \mathrm{~cm}^{-1}$ are due to methylene bridge coupled with aromatic ring. A peak at $1503 \mathrm{~cm}^{-1}$ may be ascribed to $\mathrm{N}-\mathrm{H}$ bending of secondary amide group. A sharp peak noticed at $1550.61 \mathrm{~cm}^{-1}$ may be due to $\mathrm{C}=\mathrm{N}$ stretching vibration. 


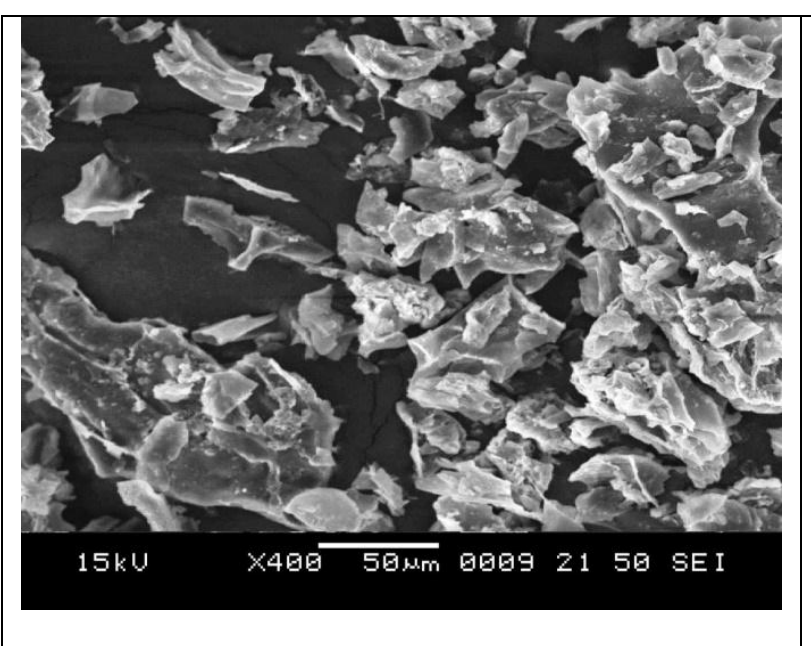

Fig. 1:- SEM of ACBCB

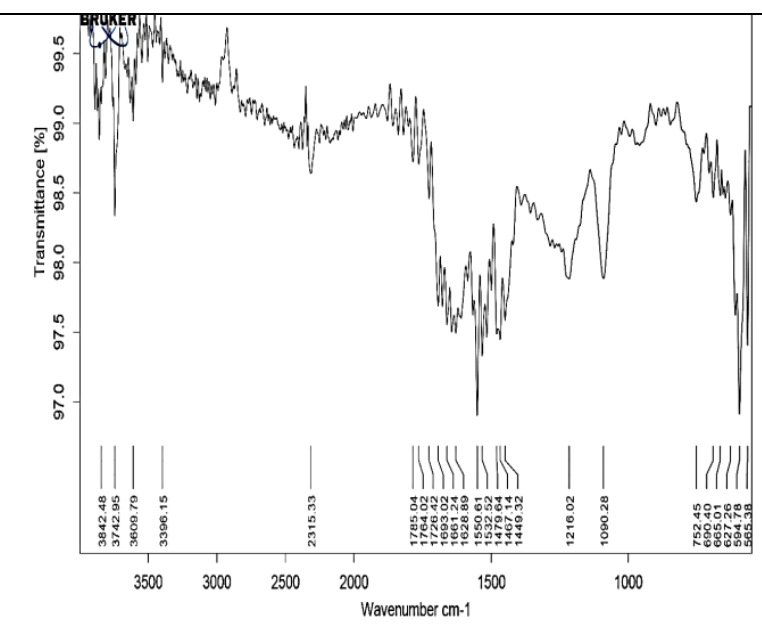

Fig 2:- FTIR Spectrum of ACBCB

\section{Results and Discussion:-}

Effect of contact time Adsorption experiments were conducted as a function of contact time and results have shown in Fig.3. It can be seen that $\mathrm{Cr}(\mathrm{VI})$ ion removal efficiency of activated carbon derived from the bark of Bombax ceiba(ACBCB) was greater in the initial stages then gradually increased upto $97.8 \%$ and remains almost constant, after optimum period of $110 \mathrm{~min}$.

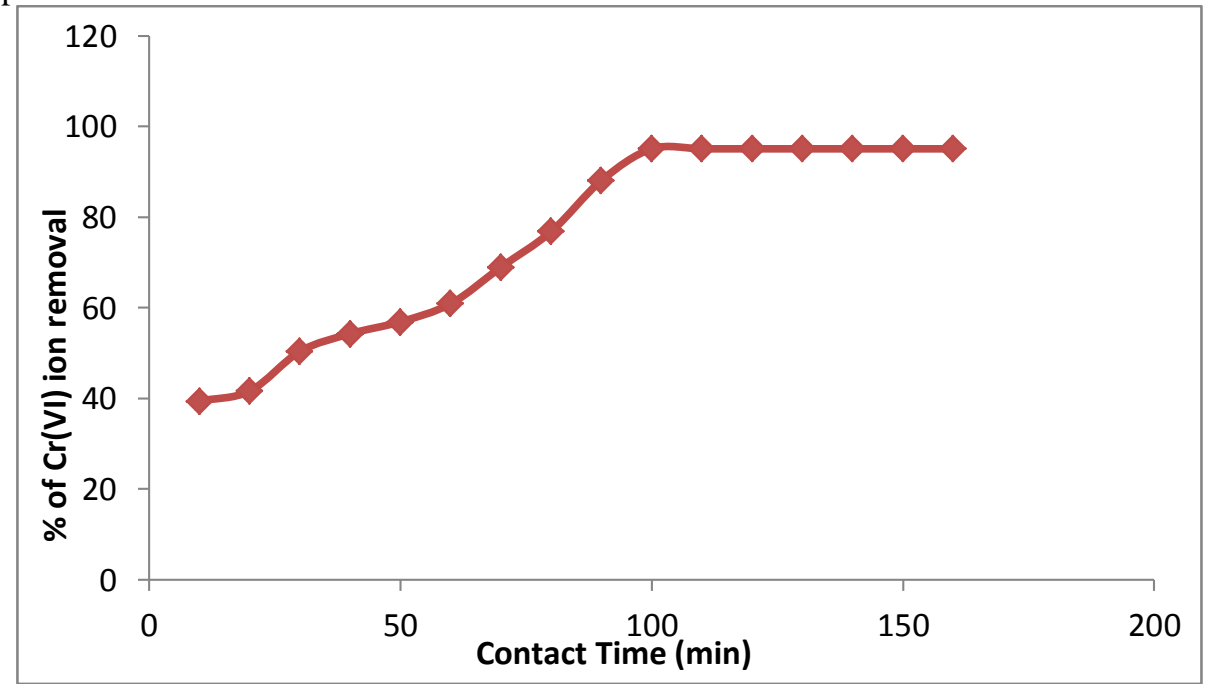

Fig3:- Effect of contact time on $\mathrm{Cr}(\mathrm{VI})$ ion removal by activated carbon derived from the bark of Bombax ceiba

\section{Effect of pH:-}

Effect of $\mathrm{pH}$ on $\mathrm{Cr}(\mathrm{VI})$ ion adsorption using activated carbon derived from the bark of Bombax ceiba 'ACBCB' has been studied in the $\mathrm{pH}$ range 1 to 10 and presented in Fig.4. The $\mathrm{pH}$ of the aqueous solution is one of the key factors that control the adsorption process of $\mathrm{Cr}(\mathrm{VI})$ ion. $\mathrm{Cr}(\mathrm{VI})$ ion removal efficiency was found $97.8 \%$ at $\mathrm{pH} 5.5$ and slowly decreases on further increases in $\mathrm{pH}$. Maximum adsorption of $\mathrm{Cr}(\mathrm{VI})$ ion was observed at the acidic $\mathrm{pH}$. This is because at lower $\mathrm{pH}$ there is increase in concentration of $\mathrm{H}^{+}$ions on the carbon surface. 


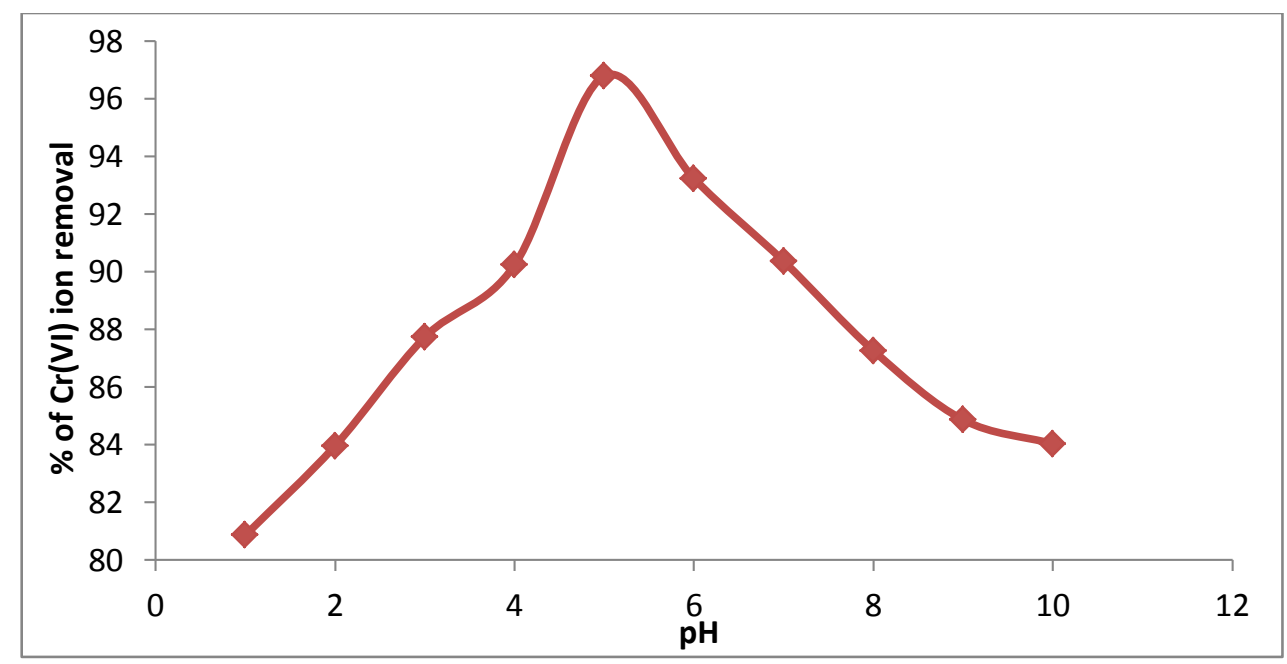

Fig4:-Effect of $\mathrm{pH}$ on $\mathrm{Cr}(\mathrm{VI})$ ion removal by activated carbon derived from the bark of Bombax ceiba

\section{Effect of Adsorbent Dosage:-}

The effect of adsorbent doses on percent removal of $\mathrm{Cr}(\mathrm{VI})$ in the range 1 to $10 \mathrm{gm}$ is represented in Fig.5. The obtained results reveal that the percentage removal of $\mathrm{Cr}(\mathrm{VI})$ ions increased with an increase in the adsorbents dose but after certain adsorbent dose it becomes constant and it is treated as an optimum adsorbent dose. Maximum adsorption was observed at $7 \mathrm{gm} / \mathrm{lit}$ i.e. $97.8 \%$. Thus $7 \mathrm{gm} / \mathrm{lit}$ is optimum adsorbent dose for 'ACBCB' adsorbent.

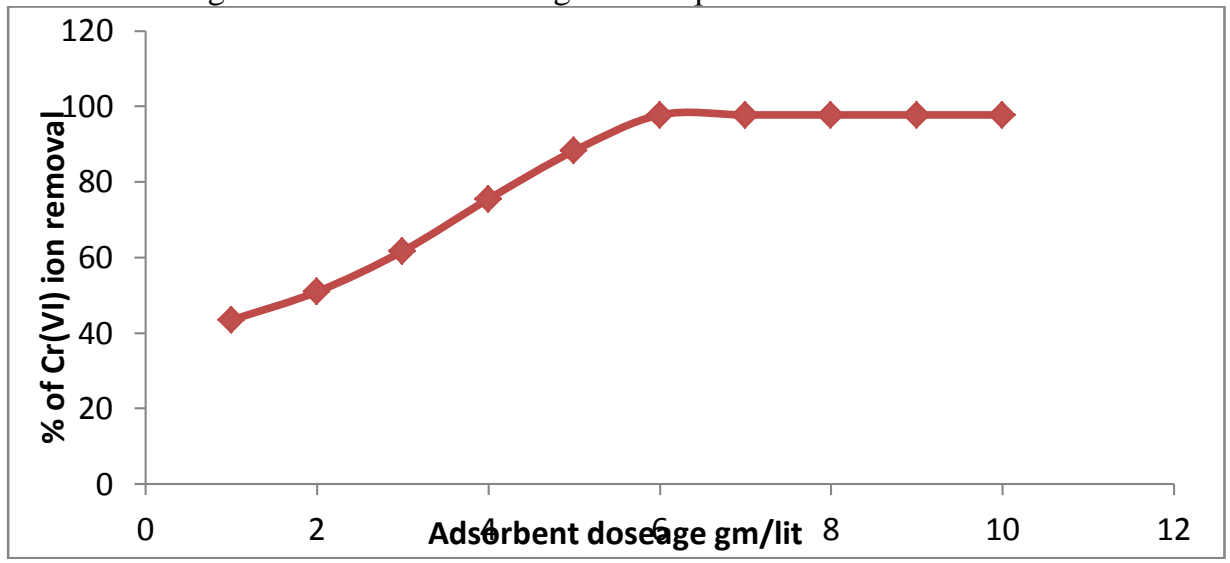

Fig 5:- Effect of adsorbent dose on $\mathrm{Cr}(\mathrm{VI})$ ion removal by activated carbon derived from the bark of Bombax ceiba

\section{Adsorption Isotherms:-}

Adsorption isotherms can be generated based on numerous theoretical models where Langmuir and Freundlich models are the most commonly used.

\section{Langmuir Isotherm:-}

The results obtained from Langmuir model for the removal of $\mathrm{Cr}(\mathrm{VI})$ ion by ACBCB has been represented in Fig.6. The adsorption efficiency 'Qm' value for $\mathrm{Cr}(\mathrm{VI})$ ion was found to be $10.449 \mathrm{mg} / \mathrm{g}$ while value of ' $\mathrm{b}$ ' was 0.175 . The lower values of $b$ (less than one) implies an excellent the affinity between solute and sorbent sites. The value of square of the correlation coefficient $\left(\mathrm{R}^{2}\right)$ is found to be 0.9782 for $\mathrm{Cr}(\mathrm{VI})$, which show the best fitting of equilibrium data. To confirm the adsorbility of the adsorption process, the equilibrium parameter also called separation factor ' $\mathrm{R}_{\mathrm{L}}$ ' for $\mathrm{Cr}(\mathrm{VI})$ was calculated. The value of $\mathrm{R}_{\mathrm{L}}$ lies between 0 and 1 for favourable adsorption, while $\mathrm{R}_{\mathrm{L}}>1$ represents favourable adsorption and $\mathrm{R}_{\mathrm{L}}=1$ represents linear adsorption while the adsorption process is irreversible if $\mathrm{R}_{\mathrm{L}}=0$. The dimensionless parameter $\mathrm{R}_{\mathrm{L}}$ values lies between 0.160 is consistent with the requirement for favourable adsorption. 


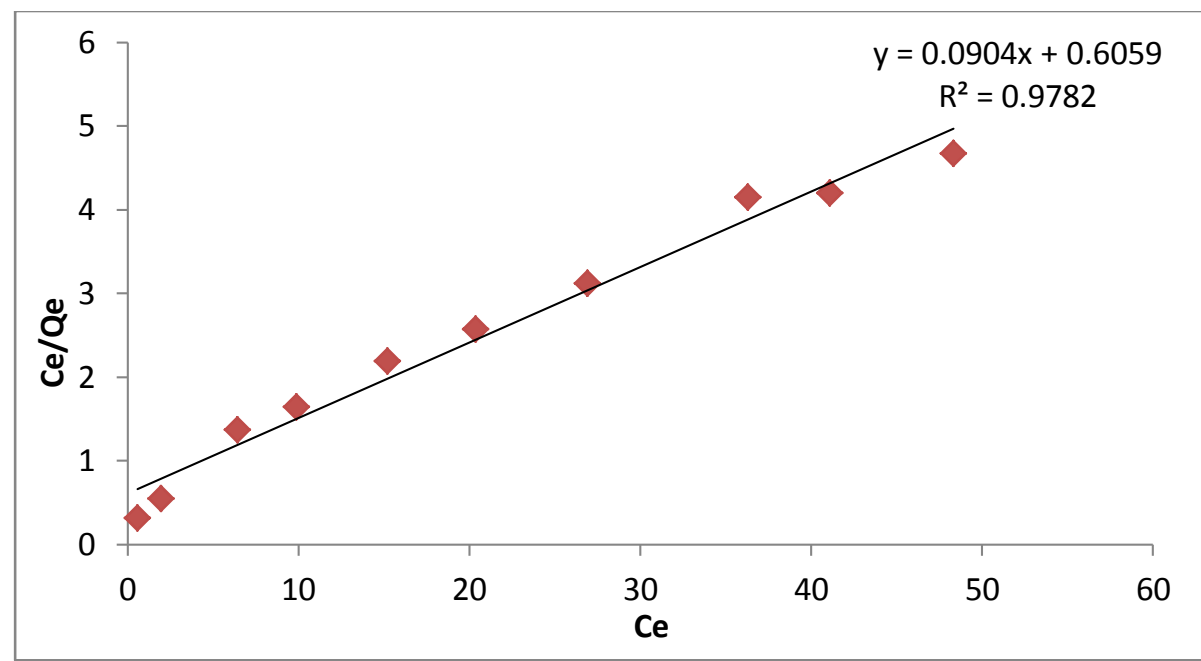

Fig6:-Langmuir isotherm for the adsorption of $\mathrm{Cr}(\mathrm{VI})$ ion on activated carbon derived from the bark of Bombax ceiba.

\section{Freundlich Isotherm:-}

The plot of $\log \mathrm{Ce}$ versus log Qe for $\mathrm{Cr}(\mathrm{VI})$ is presented in Fig.7 which show linear curve with a slope of 1/n and intercept of $\log \mathrm{K}_{\mathrm{f}}$ and hence the adsorption process obeys Freundlich adsorption isotherms. Freundlich constants ' $\mathrm{n}$ ' and ' $\mathrm{K}_{\mathrm{f}}$ ' for $\mathrm{Cr}(\mathrm{VI})$ were found to be 2.485 and $2.696 \mathrm{mg} / \mathrm{g}$ respectively. The square of the correlation coefficient $\left(\mathrm{R}^{2}\right)$ value was found to be 0.9872 for $\mathrm{Cr}(\mathrm{VI})$ which shows well-fitting of the Freundlich isotherm. The ' $n$ ' value are in between 1 to 10 which indicate the favourable adsorption of $\mathrm{Cr}(\mathrm{VI})$ on ACBCB.

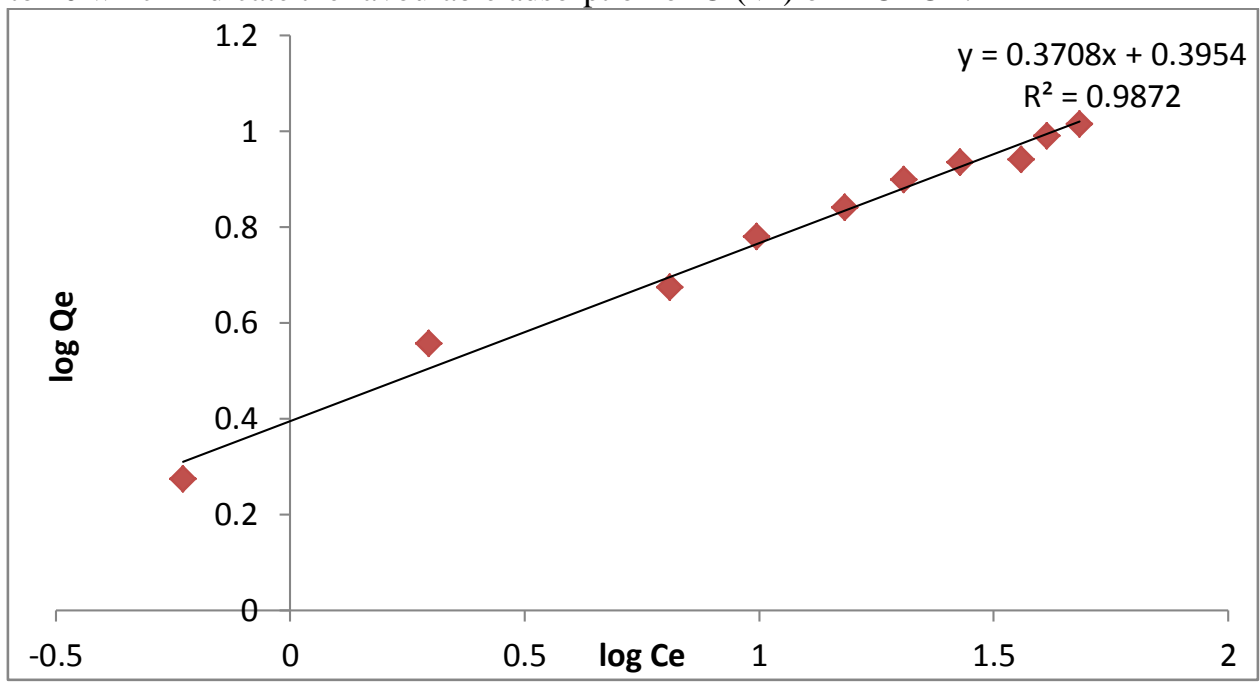

Fig 7:- Freundlich isotherm for the adsorption of $\mathrm{Cr}(\mathrm{VI})$ ion on activated carbon derived from the bark of Bombax

\section{Conclusions:-}

ceiba

Activated carbon could be successfully generated from naturally available raw material that is the bark of Bombax ceiba which has been characterized by FTIR and SEM studies and abbreviated as 'ACBCB'. The ACBCB was found to be most effective for $\mathrm{Cr}(\mathrm{VI})$ ion removal. At $\mathrm{pH} 5.5,97.8 \%$ of $\mathrm{Cr}(\mathrm{VI})$ was removed from aqueous solution and adsorption was found to be $\mathrm{pH}$ dependent. Maximum $\mathrm{Cr}(\mathrm{VI})$ removal is $97.8 \%$ for $7 \mathrm{gm} / \mathrm{lit}$ optimum adsorbent dose at $110 \mathrm{~min}$ of optimum contact time. The experimental data for the adsorption process were well fitted to the Langmuir as well as Freundlich adsorption isotherm models. Experimentally obtained appropriate values of sorption parameters derived from Langmuir isotherm like 'Qm'(adsorption efficacy), ' $b$ '(Langmuir constant), $\mathrm{R}^{2}$ (Correlation Coefficient square); and the Freundlich constant values(' $n$ ' and ' $\mathrm{K}_{\mathrm{f}}$ ') derived from Freundlich isotherm proved that the adsorbent 'ACBCB' under present investigation is the best one for efficient removal of $\mathrm{Cr}(\mathrm{VI})$ from aqueous solution. Thus the newly generated Bombax ceibabark based activated carbon $(\mathrm{ACBCB})$ reported in this research article has been proved to be an excellent eco-friendly and low-cost adsorbent 
material which can be successfully used for elimination of Carcinogenic Hexavalent Chromium from contaminated water and has potential applications in the field of water pollution control.

\section{Acknowledgement:-}

One of the author, Donadkar D.K., is thankful to the Principal and Head of the Chemistry Department, Priyadarshini College of Engineering, Nagpur, India for providing the necessary laboratory and library facilities.

\section{References:-}

1. Swathi A Patel "Removal of Heavy Metal Using Natural Adsorbents", 2012 M.Tech thesis

2. P.V.Hemalatha, P.V.V.Prasada Rao "Adsorption Batch Studies on Calcined Brick Powder in Removing Chromium and Nickel Ions". IJARCS. vol 1, pp 14-21,2014.

3. V. K. Gupta, A. Rastogi, and A. Nayak, "Adsorption studies on the removal of hexavalent chromium from aqueous solution using a low cost fertilizer industry waste material," Journal of Colloid and Interface Science, vol. 342 , no. 1, pp. 135-141, 2010.

4. W.-Q. Wang, M.-Y. Li, and Q.-X. Zeng, "Thermodynamics of $\mathrm{Cr}(\mathrm{VI})$ adsorption on strong alkaline anion exchange fiber," Transactions of Nonferrous Metals Society of China, vol. 22, no. 11, pp. 2831-2839, 2012.

5. R. Dobrowolski and M. Otto, "Study of chromium(VI) adsorption onto modified activated carbons with respect to analytical application," Adsorption, vol. 16, no. 4-5, pp. 279-286, 2010.

6. J. O. Nriagu and E. Nieboer, "Chromium," in Natural and Human Environment, Wiley, New York, NY, USA, 1988.

7. A. Mansri, K. I. Benabadji, J. Desbrières, and J. François, "Chromium removal using modified poly(4vinylpyridinium) bentonite salts," Desalination, vol. 245, no. 1-3, pp. 95-107, 2009.

8. Baran A., E. Bıçak, Ş. Hamarat-Baysal and S. Önal. Comparative studies on the adsorption of $\mathrm{Cr}(\mathrm{VI})$ ions on to various sorbents. Bioresour. Technol. 98: 661-665, 2006.

9. Demiral H., İ. Demiral, F. Tümsek and B. Karabacakoğlu. Adsorption of chromium (VI) from aqueous solution by activated carbon derived from olive bagasse and applicability of different adsorption models. J. Chem. Eng. 144: 188-196, 2008.

10. Donadkar D. K., Rahangdale P. K., Gour K., "Purification of Cr (VI) Contaminated Water Using FRBAC as Low Cost Adsorbent," Der Pharma Chemica, 8(10):230-235, 2016.

11. Donadkar D, Gour K.,Ranghdale P.K.,"Adsorption of Cadmium and Chromium Ions from Wastewater by Datura (Datura Stramonium) fruit shell," IJETT,Vol. 34 (5): 2016.

12. Vilayatkar N.D, Rahangdale P.K, Donadkar D.K., "Adsorption of Cadmium(II) from solution onto activated carbon prepared from Madhucalongifolia Fruit Shell," IJAR, Volume 4, Issue 5, 1360-1364, 2016

13. Cumming and Kay. (1948) Quantitative chemical Analysis 10th Edn.

14. A.I. Vogel, Vogel's textbook of quantitative inorganic analysis: Prentice Hall, 1978, 4th edn. ELBS. 